\title{
Turner, Marion. (2019). Chaucer: A European Life. Princeton: Princeton University Press.
}

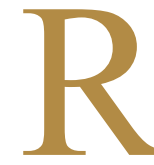

esulta difícil no pensar en Geoffrey Chaucer como un epítome temprano de lo inglés; al menos así lo dictan las narrativas culturales en torno a su obra. Sin embargo, como todo autor vernáculo medieval, Chaucer entabló una importante conversación con toda Europa. No es controvertido, así, estudiar la vida y obra del autor inglés del siglo XIV en relación con otros europeos de su época: Boccaccio, Petrarca, Froissart, Machaut o el español Pedro López de Ayala. A diferencia de lo que sucede con otros escritores medievales ingleses, la vida de Chaucer ha podido analizarse de manera más o menos razonable porque consta en registros históricos; es preciso recordar la privilegiada posición del autor como diplomático, miembro de la corte de Eduardo III y servidor público. La más reciente biografía de Geoffrey Chaucer, no obstante, propone contar la historia del autor más allá del espacio tradicional del canon y peregrina - como si se tratara de algún personaje salido de sus cuentos- a través de un viaje que transporta al lector al barrio de Vintry Ward de Londres, donde quizá nació; a su infancia en la calle Thames, en la cual se crio entre comerciantes prósperos de toda Europa; a sus recorridos por Navarra, Calais, Lombardía, Génova o Florencia, cuando fue mensajero real y diplomático; y, por supuesto, a la propia ciudad de Canterbury, que figuró de manera tan notable en su obra. Chaucer: A European Life, de Marion Turner, es una monumental reconstrucción de Geoffrey Chaucer a través de los lugares que él frecuentó durante la etapa documentada de su vida. Se trata de una feliz conjunción de historia cultural y biografía literaria que examina, como nunca, la intrincada trama política, social y textual que rodeó al escritor inglés mejor conocido de la Edad Media.

A lo largo de las 600 páginas del texto, Turner parte de un interesante principio metodológico: en primer lugar, su prólogo establece con claridad que el objetivo no consiste en narrar la vida de Geoffrey Chaucer de manera estrictamente cronológica sino recrear, en la medida de lo posible, los contextos que sirvieron de inspiración al autor $y$, en sus propias palabras, "[t]he spaces and institutions in which Chaucer lived and worked, and the places that he visited, shaped him as a person and as a poet" (3). De esta forma, podría decirse que la autora, catedrática de la Universidad de Oxford, trae a cuento la misma postura hermenéutica bajo la cual trabajaba un cronista medieval: contar los hechos no exactamente como sucedieron, sino colorear la escritura mediante estrategias discursivas y retóricas que permitieran al texto cabalgar entre la historia y 
la ficción. Por otro lado, Turner desmiente la extendida visión de Chaucer como un fenómeno exclusivamente inglés (discurso, por ejemplo, que durante siglos imperó en la manera en que se leyó o estudió al escritor) para centrarse sobre todo en la imagen de un autor abierto, sensible, cosmopolita y políglota que se nutrió tanto de su ambiente local como de un mundo complejo y multicultural.

El estudio de Turner está dividido en tres grandes partes: Becoming, Being y Approaching Canterbury. En cada una de estas secciones, hay pequeños capítulos que trazan con singular sutileza y erudición, pero también con una inmensa dosis de humor, escepticismo e ironía, el panorama cultural que acompañó los momentos clave de la historia de Chaucer. La biógrafa nos recuerda, en este sentido, que la vida del autor fue posiblemente compleja y rica desde su infancia, pues al ser hijo de un acomodado mercader de vino, Chaucer se movió siempre en el seno de una clase urbana y burguesa. Esto no resulta especialmente novedoso: todas las biografías o estudios sobre la vida del poeta, académicas o no, rescatan tal hecho. Lo que se antoja más atractivo es la cuidadosa mirada que Turner cierne sobre el Londres de mediados del siglo XIV: una ciudad donde florecieron la burocracia, la inmigración o el comercio exterior y que fue un pujante centro de letras y lenguas. En un ambiente en que el dinero constituyó un importante marcador de identidad, los libros se convirtieron en un importante bien de consumo. Turner señala que el caso de Londres era único con respecto al resto de Inglaterra, pues la población valoraba los libros en cuanto objetos ornamentales y de lujo, pero también como instrumentos de aprendizaje lo mismo laico que religioso.

Asimismo, la autora no descuida el hecho de que, quizá como en ningún otro momento de la historia reciente de Inglaterra, el inglés había resurgido como principal lengua literaria de la nación y esto catapultó la obra de Chaucer. Aun así, añade que el inglés no fue del todo lo que transformó la poesía del autor, sino su contacto temprano con ciudadanos y mercaderes italianos: “...Chaucer's Thameside mercantile upbringing gave him the opportunity to mix with Italians and to learn their language - a skill that was to transform not only Chaucer's own poetry but English literature" (17). Con ello, Turner da un revés fundamental y necesario a la historiografía literaria inglesa al dislocar una narrativa que se imaginó sobre Chaucer por lo menos desde el siglo XVIII y que sobrevive hasta nuestros días: la de Chaucer como una suerte de padre moderno de la lengua y la poesía inglesa. ${ }^{1}$ La especialista, cabe añadir, no hace mención explícita de este discurso redentor sobre el poeta, pero al imaginar a Chaucer como un hombre políglota de origen y, sobre todo, como un gran deudor de otras tradiciones lingüísticas y textuales, establece el tono con el que guía el resto de tan completa biografía.

\footnotetext{
Me refiero en concreto a John Dryden, quien en sus Fables, Ancient and Modern, de 1700, registra por primera vez el epíteto de "father of English poetry" para describir a Chaucer.
} 
Esta primera parte del texto constituye tal vez la más nutrida en curiosidades si consideramos el recorrido que Turner traza por las que podrían haber sido la infancia y adolescencia de Chaucer. Después de imaginar brevemente el contacto del niño Geoffrey con las primeras letras y los aprendizajes a los cuales sin duda estuvo expuesto cuando asistió por primera vez a la escuela (nos habla, por ejemplo, de la enseñanza típica de un niño medieval de clase media), el libro hace hincapié en una indudable educación plurilingüe. Ciertamente, la escolarización temprana en las ciudades inglesas hacia 1350 ya ocurría en la lengua nacional, pero cualquier contacto con el mundo de los libros debía contemplar necesariamente el latín y en particular el francés, principal lengua política y literaria de Inglaterra durante casi tres siglos medievales. Por lo tanto, el Chaucer de 1355, con apenas unos catorce o quince años, habría disfrutado de un ambiente urbano, una considerable fortuna familiar y el privilegio de una educación escolarizada. Hacia esta época, la vida del autor cambió de forma considerable cuando emprendió una carrera de negocios al lado de su padre y fueron las mismas conexiones familiares las que lo condujeron a la corte de Eduardo III y su consorte francesa Felipa de Henao. Como argumenta más adelante Turner, el Condado de Henao (Hainault, por su nombre en inglés y francés) resulta de vital importancia para entender acontecimientos de la historia posterior de Chaucer, pues fue la tierra natal de su esposa Felipa de Roet, con quien el poeta contrajo matrimonio alrededor de 1357 cuando servía aún en la corte donde Felipa fungía como dama de compañía.

Sin duda, uno de los componentes más originales de la biografía de Turner es la hábil manera en la que mezcla elementos literarios de la obra de Chaucer con episodios notables de su propia historia de vida como si se tratara de un ejemplo de historiografía del medioevo. Me atrevo a decir que son cientos los ejemplos relevantes y no que hay obra, célebre o menor, que no explore Turner en su análisis. Conviene traer a colación, aquí, la metáfora que se utiliza para describir la relación temprana entre el escritor y Filipa. La privacidad, indica el libro, no era un valor importante en el siglo XIV de la misma forma en que lo es hoy, y esto habría representado obstáculos para los jóvenes Geoffrey y Felipa. Turner alude, para esto, a un curioso momento del poema cortés Troilo y Criseida. Se cree que éste fue uno de los primeros romances ingleses en describir a cabalidad el uso de armarios en cámaras privadas (Criseida dispone de una en el texto) y que, de tal forma, Chaucer, sostiene la autora, conjuga satisfactoriamente lo público y lo privado en su obra debido a que probablemente careció de ello durante mucho tiempo en su vida, incluso tras haber construido matrimonio (52). De hecho, cualquier lector cauto de la obra del poeta londinense sabe que hablar de espacios privados y lugares públicos no es gratuito a la hora de analizar sus cuentos o poemas. Después de todo, no hay texto chauceriano que no avance una temática explícita a la luz de estos dos mundos que, aunque aparentemente contradictorios, conforman una 
directriz fundamental para entender la Edad Media de Chaucer: antes de convertirse en poeta, Geoffrey conoció íntimamente el centro de la vida política de Inglaterra; más que ningún otro autor hasta el momento. $\mathrm{Y}$ aunque son varios los atisbos a su vida privada en el texto, Turner deja en claro que no pretende hacer una disquisición, en tanto consiste en un ejercicio fútil, sobre la posible vida emocional del autor.

Posteriormente, la especialista ofrece un recuento riguroso, con interpretaciones políticas, sobre algunos de los principales viajes por Europa que realizó Geoffrey Chaucer, aunque el énfasis de la historia está puesto en los capítulos anteriores. Sabemos, por registros civiles, que el poeta visitó en más de una ocasión Francia e Italia. Aquí es preciso mencionar un ligero desfase cronológico: Chaucer se casó en 1366 y antes ya había emprendido misiones a Calais y a Reims, donde fue capturado como miembro del ejército inglés durante la llamada Guerra de los Cien Años contra Francia. Poco después de su matrimonio, pasó una temporada larga en Navarra. En la última década, la estancia de Chaucer en España ha sido objeto de un renovado interés académico, sobre todo porque a la hora de reconstruir el rompecabezas europeo del autor, España ha ocupado un lugar coyuntural para los críticos y el estudio de Turner cambia el curso de la historia por completo. En particular la autora resalta las posibilidades de lectura a la luz del cronista castellano Pedro López de Ayala, originalmente al servicio de Pedro I de Castilla, monarca que queda inmortalizado en un fragmento del "Cuento del monje".

La última parte del texto, Being, echa mano del peregrinaje anterior para concentrarse en aspectos específicos de la vida de Chaucer como poeta. Es imposible, de esta forma, olvidar que el escritor de los Cuentos de Canterbury siempre mezcló su figura pública con la condición de celebridad que obtuvo tras escribir Troilo y Criseida en 1369. La mayoría de los estudiosos sitúa la escritura de su famosa colección de cuentos hacia 1387 (sabemos bien que la composición de estos no sucedió de forma lineal), pero si algo resulta evidente de la interpretación de Turner es que Chaucer fue quizá el primer gran autor moderno europeo en un sentido amplio: no hay lectura posible, de ninguno de sus poemas, que no quede en deuda con Europa. Al obligarnos a mirar más allá de Londres o del Tabard Inn — desde donde sus personajes inician el recorrido hacia Canterbury-, pero en especial, al deconstruir un personaje que la historia cultural nos ha dicho que inventó la idea de lo vernáculo en Inglaterra, Marion Turner, primera biógrafa (y aquí es importante, me parece, hacer este desdoblamiento de género) y con certeza, autora de la más llamativa historia sobre el autor originario del Vintry Ward de Londres, cambia el curso del peregrinaje para que, al igual que sucede con los divertidos viajeros de sus relatos, nos sorprenda un cuento en el camino.

Raúl Ariza Barile Universidad Nacional Autónoma de MéXico | México 